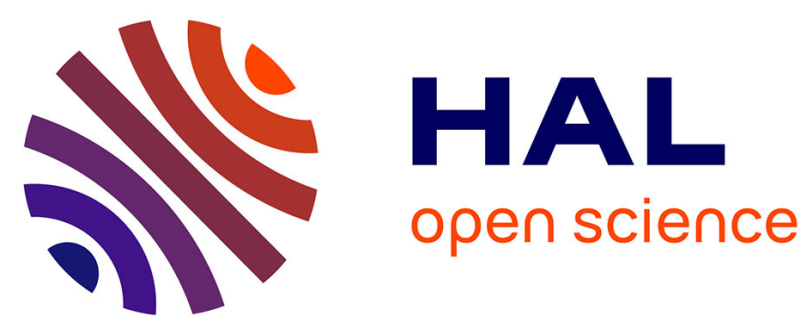

\title{
LIQUID CRYSTAL IMAGE CONVERTER BASED ON THE CHOLESTERIC-NEMATIC PHASE TRANSITION WITH STORAGE
}

\author{
G. Chilaya, D. Siharulidze, M. Brodzeli
}

\section{- To cite this version:}

G. Chilaya, D. Siharulidze, M. Brodzeli. LIQUID CRYSTAL IMAGE CONVERTER BASED ON THE CHOLESTERIC-NEMATIC PHASE TRANSITION WITH STORAGE. Journal de Physique Colloques, 1979, 40 (C3), pp.C3-274-C3-277. 10.1051/jphyscol:1979352 . jpa-00218748

\section{HAL Id: jpa-00218748 https://hal.science/jpa-00218748}

Submitted on 1 Jan 1979

HAL is a multi-disciplinary open access archive for the deposit and dissemination of scientific research documents, whether they are published or not. The documents may come from teaching and research institutions in France or abroad, or from public or private research centers.
L'archive ouverte pluridisciplinaire HAL, est destinée au dépôt et à la diffusion de documents scientifiques de niveau recherche, publiés ou non, émanant des établissements d'enseignement et de recherche français ou étrangers, des laboratoires publics ou privés. 


\title{
LIQUID CRYSTAL IMAGE CONVERTER BASED ON THE CHOLESTERIC-NEMATIC PHASE TRANSITION WITH STORAGE
}

\author{
G. S. CHILAYA, D. G. SIHARULIDZE and M. I. BRODZELI \\ Institute of Cybernetics Academy of Sciences of Georgian SSR, Tbilisi 380086, S. Euli str. 5, USSR
}

\begin{abstract}
Résumé. - Un convertisseur d'images (CI) basé sur la combinaison de la structure du type semiconducteur-diélectrique et cristal liquide est examiné. Les caractéristiques particulières de ce convertisseur d'images sont l'utilisation des semiconducteurs aux zones étroites et le court temps d'exposition non limité par l'inertie du cristal liquide. L'utilisation de l'effet électro-optique, celui de la transition de la phase cholestérique-nématique, a quelques avantages : le haut contraste, les basses tensions gérées, le seuil précis, la possibilité de trađuire l'image en positif ou en négatif.
\end{abstract}

\begin{abstract}
The image converter (IC) based on the combination of semiconductor-dielectric (SD) structure and liquid crystal (LC) had been described in [1]. The presence of SD structure in photosensitive part of IC, implies some original features : a) The possibility of using narrow band semiconductor $(\mathrm{Si})$ as a photosensitive material in pair with $\mathrm{LC}$ which enlarges the spectral range in infrared part of spectrum. b) Considerable decrease of image exposition time $\left(\sim 10^{-9} \div 10^{-7} \mathrm{~s}\right)$, which is not limited by inertia of LC in this type of IC.
\end{abstract}

The following electrooptic effects in LC were used in [1] : dynamic scattering, dynamic scattering with storage, S-effect. IC based on LC with cholestericnematic (CN) transition with storage is investigated here. The storage effect observed in thin cells is produced by the texture changes [2-6]. When the layer thickness being of the same order as spiral pitch $P$ the surface pinning energy is significant. As a result we have deformed spiral superstructure, called in [4] the strains structure (ST). The period of this superstructure can exceed $P$ essentially. This effect was considered for normal surface orientation of LC molecules in $[2,4,6]$ and in $[3,5]$ it was shown that ST can be obtained for the parallel orientation of LC molecules and untreated cells. In $[3,5]$ it was demonstrated that ST existence depends not only on the $d / P$ correlation, but on the influence of electric field. That is in certain cases if the initial structure is not deformed ST is formed after the nematic state. This effect is observed in the regime of electric field rapid switching off, the field voltage being more than the voltage of the $\mathrm{CN}$ transition $\left(U_{\mathrm{CN}}\right)$. When the electric field less than $U_{\mathrm{CN}}$ is applied, the confocal texture (CT) is formed. As the ST is formed also in the cells with the parallel orientation of molecules, we can observe the following texture changes : the planar texture PT $\rightarrow \mathrm{CT} \rightarrow \mathrm{ST}$. ST is more transparent than CT and darker than PT. ST as well as CT is kept a long time as a result we can get both the negative and positive image in the same cell, when the applied voltage increases. These are the advan- tages of $\mathrm{CN}$ transition effect in comparison with the effect of dynamic scattering with storage : high contrast, low drive voltage, sharp threshold, possibility of transformation of input image into a positive or negative one.

1. Experiment. - The configuration of IC is illustrated on figure 1 . The structure mentioned is just a puck like silicon monocrystal with $2 \div 3 \mathrm{~cm}$ diameter, $2 \times 10^{-2} \mathrm{~cm}$ thickness and with transparent $2 \times 10^{-5} \mathrm{~cm}$ thick dielectric $\left(\mathrm{SiO}_{2}\right)$ on both sides. The LC thickness $18 \mu \mathrm{m}$ is sandwiched between the transparent indium oxide electrode on the glass plate and dielectric-semiconductor structure. The input face of IC is covered with transparent electrodes. The nematic-cholesteric room temperature mixture with $\Delta \varepsilon>0$ and $P=3 \mu \mathrm{m}$ is used.

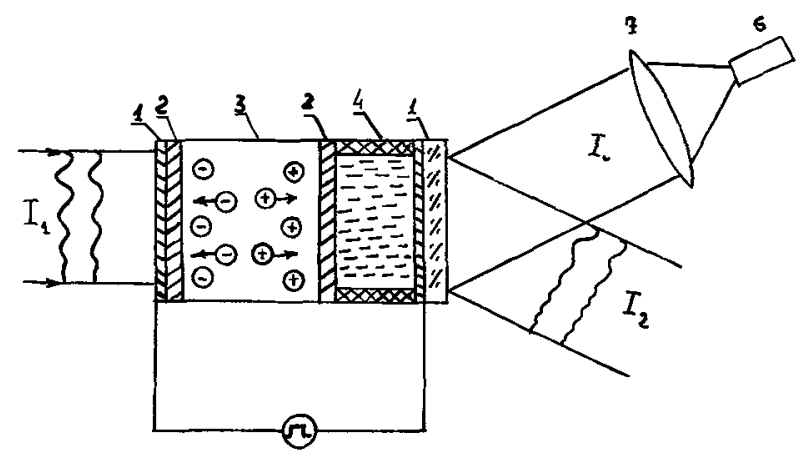

FIG. 1. - Configuration of IC. 1 : electrodes, 2 : dielectric layers, 3 : semiconductor, $4:$ LC, 5 : pulse voltage, $6:$ laser, $7:$ collimator, $I$ : input image, II : read-out image. 
The input image is formed by means of the GaAs diodes. The reading of an image is realized either through the $\mathrm{He}-\mathrm{Ne}$ laser, or white light. For the last case the suitable filters which prevent photoconductor from the read-out light beam are used. Read-out of image can be realized both in the reflective and the scattering light. Either the pulse voltage with the duration $\sim 10 \div 10^{3} \mu$ s and frequency

$$
\sim 50 \div 5 \times 10^{4} \mathrm{~Hz}
$$

or AC field with the frequency not more than $100 \mathrm{kHz}$ were applied to IC electrodes. In the combined system under the light LC goes into the nematic state, when the general voltage level is $71 \mathrm{~V}$. In this case the positive image was formed in the mirror reflected light beam and the negative image was formed in the scattering light (Fig. 2).

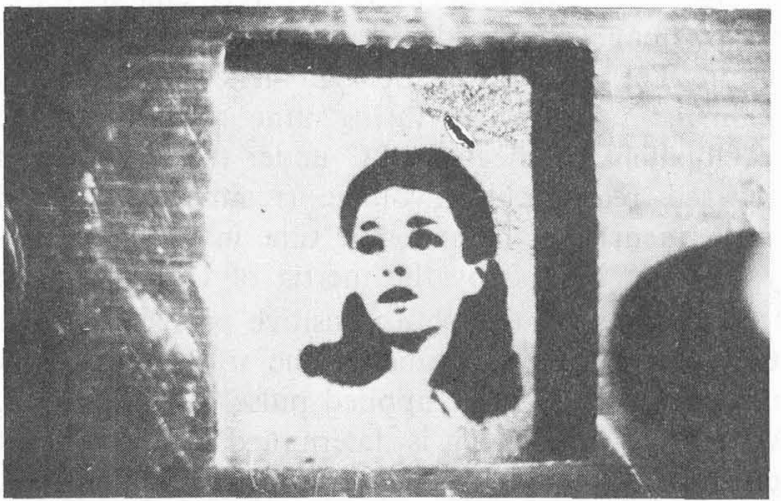

a)

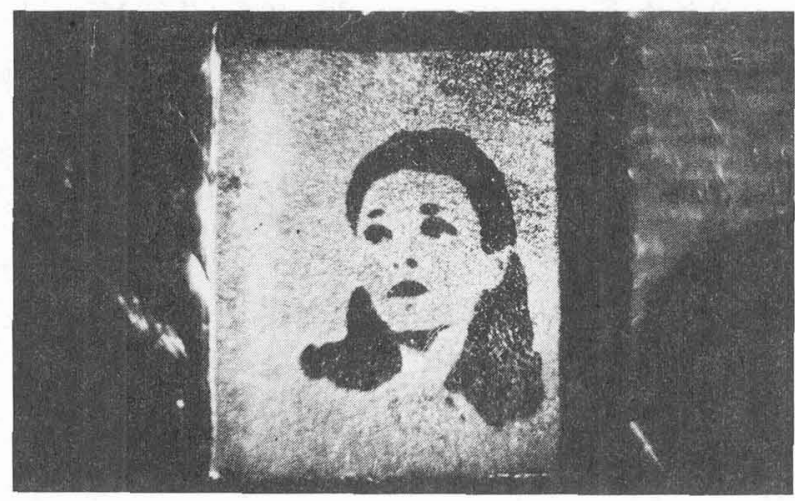

b)

FIG. 2. - A photograph of converted image in a nematic state $(a)$ and strains texture state $(b)$.

The storage effect is observed after the rapid voltage switch off some seconds later the positive image with diminished contrast $40: 1$, was formed in the mirror reflected light. Erasing and recording were realized with the help of voltage regulation. In this case there was a possibility to record down the image when the voltage applied was less than $U_{\mathrm{CN}}$ and the mentioned initial orientation had to be planar. In $18 \mathrm{~V}$ electric field we have inverse picture : the positive image is formed in the scattered light and this image is kept after the voltage switch off (Fig. 3). The erasure in this position is carried out either with the help of mechanical displacement of the substrate or through heating the system up to isotropic state and further slow cooling.

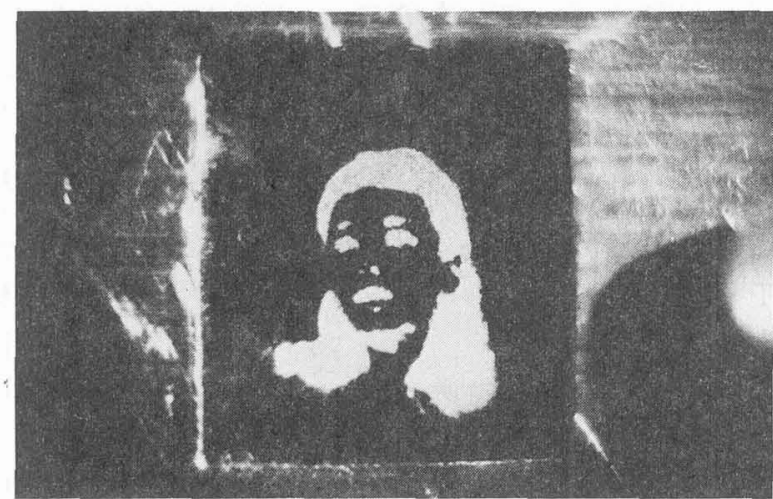

FIG. 3. - A photograph of converted image in a confocal texture state.

If the voltage more than $U_{\mathrm{CN}}$ is applied to the cell mentioned in the figure 3 , the part where image is formed goes into nematic structure and the rest part into the confocal one. The resulting picture is illustrated in figure 2.

The overall performance characteristics of the IC are : the rise time $0.2 \mathrm{~ms}(d=18 \mu \mathrm{m}, U=150 \mathrm{~V})$, maximum contrast ratio : $100: 1$, sensitivity $\sim 10^{-8} \mathrm{~J} / \mathrm{cm}^{2} .(\lambda \approx 0.9 \mu \mathrm{m}, \tau=1 \mathrm{~ms})$ and resolution 20 lines $/ \mathrm{mm}$.

2. Discussion. - Now we'll consider the layer matching conditions and the dynamic of processes. Let the voltage pulse with the amplitude $U_{0}$ be applied to the IC electrodes. Free carriers are drifted the semiconductor volume and accumulated on the layers interface. If the initial carrier concentration is not sufficient for screening of external voltage, than in the semiconductor a depleted layer arises :

$$
L_{\mathrm{d}}=\left(\frac{\varepsilon_{\mathrm{S}} U_{0}}{4 \pi q n_{0}}\right)^{1 / 2} \text {. }
$$

For $\quad U_{0} \simeq 10^{2} \mathrm{~V}, \quad n_{0} \sim 10^{12} \mathrm{~cm}^{-3}, \quad \varepsilon_{\mathrm{S}} \sim 10$, $\mathrm{L}_{\mathrm{d}} \simeq 10^{-1} \mathrm{~cm}$. Hence, when thickness of the layer of the semiconductor is $L_{\mathrm{S}} \approx 2 \times 10^{-2} \mathrm{~cm}, L_{\mathrm{d}} \gg L_{\mathrm{S}}$. The depletion is spread on the whole bulk of the semiconductor. In this case the whole voltage is distributed on the semiconductor layer and therefore there exists a strong field $E_{\mathrm{s}}=U_{\mathrm{s}} / L_{\mathrm{s}}$. In such a case the diffusion current and the space charge field can be neglected and the equation of continuity can be written as follows $[7,8]$.

$$
\frac{\mathrm{d} n}{\mathrm{~d} t}=G_{0}-\frac{n}{t_{\mathrm{dr}}}
$$


where $G_{0}=n_{0} / \tau_{0}$ is the current termogeneration speed, $\tau_{0}$, life time, $t_{\mathrm{dr}}=L_{\mathrm{S}} / \mu E_{\mathrm{S}}$, drift time. For $E_{\mathrm{S}}>E_{\text {sat }}\left(E_{\text {sat }}\right.$, voltage for carrier speed saturation) a steady state is reach in the bulk of the semiconductor. In this case all the carriers drift during a short time $t_{\mathrm{dr}} \ll \tau_{0}$ and are accumulated on the layer interface. The constant concentration of carriers $n_{\mathrm{d}}$ is established in the whole bulk of the semiconductor, which corresponds to the condition $\mathrm{d} n / \mathrm{d} t=0$ in (2).

$n_{\mathrm{d}}$ is obtained from (2)

$$
n_{\mathrm{d}}=G_{0} t_{\mathrm{dr}}
$$

and from (3) we can get the conductivity of the depleted layer multiplying both parts of (3) by $q \mu$

$$
\sigma_{\mathrm{d}}=\frac{q G_{0} L_{\mathrm{S}}^{2}}{U_{\mathrm{S}}}
$$

$\sigma_{\mathrm{d}}=10^{-10} \Omega^{-1} \mathrm{~cm}^{-1}$ for values $U_{0}=10^{2} \mathrm{~V}$, $G_{0}=10^{15} \mathrm{~cm}^{-3} \mathrm{~s}^{-1} L_{\mathrm{S}}=2 \times 10^{-2} \mathrm{~cm}$. All calculation are made for unit square. Assuming the current in semiconductor active layer resistance of semiconductor will be

$$
R_{\mathrm{S}}=\frac{1}{\sigma} L_{\mathrm{S}}=\frac{U_{\mathrm{S}}}{q G_{0} L_{\mathrm{S}}} \simeq 2 \times 10^{8} \Omega
$$

when the thickness of the layer of $\mathrm{LC}$ is $L_{\mathrm{LC}} \simeq 10^{-3} \mathrm{~cm}$ and $R_{\mathrm{LC}}=10^{-3} \mathrm{~cm} \times 10^{9} \Omega . \mathrm{cm}^{-1}=10^{6} \Omega$. Hence it is clear that in this regime the necessary condition $R_{\mathrm{S}}>R_{\mathrm{LC}}$ for IC functioning holds in the dark state.

The input image causes the photogeneration of carriers in semiconductor which drift into the bulk of semiconductor and are accumulated on the interface of layers. The carriers accumulated screen the field in semiconductor and redistribute it on the LC layer. The equations which describe the distribution of voltage on the layers are of the form :

$$
\begin{gathered}
C_{\mathrm{LC}} U_{\mathrm{LC}}=C_{\mathrm{S}} U_{\mathrm{S}}+q N_{\mathrm{S} \mathrm{r}} \\
U_{0}=U_{\mathrm{S}}+U_{\mathrm{LC}}
\end{gathered}
$$

$L_{\mathrm{d}} \ll L_{\mathrm{LC}}, L_{\mathrm{S}}$ and hence we neglect the voltage distributed on the dielectric layer. For the LC layer voltage we have :

$$
U_{\mathrm{LC}}=\frac{C_{\mathrm{S}}}{C_{\mathrm{LC}}} U_{0}+\frac{q N_{\mathrm{Sr}}}{C_{\mathrm{LC}}}
$$

$C_{\mathrm{S}}, C_{\mathrm{LC}}$ are the geometrical capacities of semiconductor layer and LC layer respectively, $N_{\mathrm{Sr}}=N_{\mathrm{SO}}+N_{\mathrm{SPh}}$ the surface density of carriers, $N_{\mathrm{S} 0}=n_{0} L_{\mathrm{S}}+G_{0} L_{\mathrm{S}} t_{\mathrm{i}}$, surface density of carriers, determined by the initial concentration of carriers and the dark current of termogeneration of semiconductor $N_{\mathrm{SPh}}=G_{\mathrm{Ph}} L_{\mathrm{S}} \Delta t_{\mathrm{Ph}}$ is the value of the surface density of carriers, created with time $\Delta t_{\mathrm{Ph}}$ by the influence of the input image, where the speed of photogeneration current is $G_{\mathrm{Ph}}$. Taking into account $N_{\mathrm{Sn}}$ (7) takes the form :

$$
\begin{aligned}
U_{\mathrm{LC}}= & \frac{C_{\mathrm{S}}}{C_{\mathrm{LC}}} U_{0}+ \\
& +\frac{q n_{0} \cdot L_{\mathrm{S}}}{C_{\mathrm{LC}}}+\frac{q G_{0} L_{\mathrm{S}} t_{\mathrm{i}}}{C_{\mathrm{LC}}}+\frac{q G_{\mathrm{Ph}} L_{\mathrm{S}} \Delta t_{\mathrm{Ph}}}{C_{\mathrm{LC}}} .
\end{aligned}
$$

The image registration time is determined in the structures of semiconductor by the carriers drift time in the semiconductor :

$$
t_{\mathrm{dr}}=\frac{L_{\mathrm{S}}^{2}}{\mu E_{\mathrm{S}}} .
$$

For silicon with values

$$
L_{\mathrm{S}} \sim 2 \times 10^{-2} \mathrm{~cm}, \quad U_{\mathrm{S}} \sim 10^{2} \mathrm{~V}, \quad t_{\mathrm{dr}} \sim 10^{-9} \mathrm{~s} .
$$

This is the shortest time, needed for the exposure of an image. The charge created by the light and the voltage redistribution caused by this charge (electronic image) holds during all the time of pulse action. The reaction of $\mathrm{LC}$ and hence, the forming of image takes place during time needed for the development of effects in LC under the influence of storaged redistributed voltage (regime of delayed displayment). So the exposure time in the IC of this type is not limited by the inertia of LC. This time depends only on the photosensitive part of IC. The IC works during the time of the transition (instationary) process, while applied pulse of the voltage. After some time which is determined by the time of screening of the field by the termogeneration current, the stationary state is established and IC stops working. So the working regime of IC is the dynamic one. Which implies the necessity of feeding IC with the pulse voltage. The duration of the pulse must not exceed the time of the stationary state establishing. This time can be calculated from the field screening condition $(8)$ where $U_{\mathrm{S}}=0, U_{\mathrm{LC}} \approx U_{0}$, $G_{\mathrm{Ph}}=0$ and $\left(C_{\mathrm{S}} / C_{\mathrm{LC}}\right) U_{0}$ neglected :

$$
t_{\mathrm{SCr}}=\tau_{0}\left(\frac{N_{\mathrm{S}_{\mathrm{m}}}}{N_{\mathrm{So}}}-1\right) \text {. }
$$

Here $N_{S_{\mathrm{m}}}=C_{\mathrm{LC}} U_{\mathrm{o}} / q$ is the maximally possible surface density of accumulated carriers, which screen all the field of semiconductor.

$N_{\mathrm{SO}}=n_{0} L_{\mathrm{S}}$ the initial surface density of carriers determined by the initial concentration $n_{0}, \tau_{0}$ is the life time. For silicon, if $\tau_{0} \sim 10^{-4} \mathrm{~s}$,

$$
\begin{aligned}
n_{0} & \sim 10^{12} \mathrm{~cm}^{-3}, L_{\mathrm{S}} \sim 2 \times 10^{-2} \mathrm{~cm}, \\
L_{\mathrm{LC}} & \sim 10^{-3} \mathrm{~cm} \text { the } t_{\mathrm{SCr}} \sim 3 \times 10^{-3} \mathrm{~s} .
\end{aligned}
$$

So, the duration of voltage pulse is defined by the condition $t_{\mathrm{imp}}<t_{\mathrm{SCr}}$. We can get the threshold sensitivity from (8) were the first 3 members define the value of the dark state voltage on the LC layer

$$
U_{\text {dark }}=\frac{C_{\mathrm{S}}}{C_{\mathrm{LC}}} U_{0}+\frac{q n_{0} L_{\mathrm{S}}}{C_{\mathrm{LC}}}+\frac{q G_{0} L_{\mathrm{S}} t_{\mathrm{i}}}{C_{\mathrm{LC}}} .
$$


For the transition to the nematic state we must redistribute the voltage $U_{\mathrm{sw}}=U_{\mathrm{N}}-U_{\mathrm{dark}}$ on the $\mathrm{LC}$ layer. This voltage is defined by the light influence

$$
U_{\mathrm{Ph}}=\frac{q G_{\mathrm{Ph}} L_{\mathrm{S}} \Delta t_{\mathrm{Ph}}}{C_{L C}}=\frac{q N_{\mathrm{SPh}}}{C_{\mathrm{LC}}} .
$$

The value threshold energy is equal to the energy of the radiation, which forms $N_{\mathrm{SPh}}$

$$
E_{\mathrm{thr}}=\gamma h v N_{\mathrm{SPh}}=\gamma h v \frac{C_{\mathrm{LC}} U_{\mathrm{Ph}}}{q}
$$

where $\gamma$ is a coefficient of internal photoeffect, is a energy of light quant. If $\gamma \approx 1, h v \sim 10^{-19} \mathrm{~J}$, $C_{\mathrm{LC}} \sim 10^{-9} \varphi$ and $U_{\mathrm{SW}}$ is taken $\sim 20 \mathrm{~V}$ than $E_{\mathrm{thr}} \simeq 10^{-8} \mathrm{~J} / \mathrm{cm}^{2}$. With the suitable frequency of voltage pulse we can reach the following regime : the image formed during only one pulse has no time to relaxe by the time of the following pulse through the electric image is formed and relaxes with every voltage pulse. In this case a stationary image in LC is observed, which corresponds to the sum of all pulse images.

IC on the base structure of semiconductor-dielectric and LC type owing to its functional possibilities and easy technologics have prospects in optical data processing systems.

\section{References}

[1] a) Siharulidze, D. G., Chilaya, G. S., Hostaria, D. G., BRodzel, M. I., Second liquid crystal conference of socialist countries, Sunny Beach, September 27-30 (1977) 308-309.

b) Authors certificate, N 580778, Filed 30. VII (1975).

[2] Greubel, W., Appl. Phys. Lett. 25 (1974) 5.

[3] Chilaya, G. S., Siltarulidze, D. G., JTP Letters 4 (1978) 384.

[4] Press, M. I., Arrott, A. S., J. Physique 37 (1976) 384.

[5] Chilaya, G. S., Aronishidze, S. N., Vinokur, K. D.,
Ivchenko, S. P., Brodzeli, M. I., Second Liquid Crystal Conference of Socialist countries, Sunny Beach, September 27-30 (1977) 126-127.

[6] Belyeaev, S. V., Rumiantsey, V. G., Belyaev, V. V., $Z h$. Eksp. Teor. Fiz. 73 (1977) 644.

[7] Kovtoniuk, N. F., Fiz. Tekh Polupr. 8 (1974) 267.

[8] Siharulidze, D. G., Brodzeli, M. I., Trudy Inst. Cybern. Acad. Nauk GSSR, Tbilisi III (1977) 11-33. 